EGU2020-18614

https://doi.org/10.5194/egusphere-egu2020-18614

EGU General Assembly 2020

(c) Author(s) 2021. This work is distributed under

the Creative Commons Attribution 4.0 License.

\title{
Shallow landslides involving weathered and fractured bedrock: a comparative susceptibility analysis between deterministic and statistical models
}

\author{
Enrico D'Addario ${ }^{1}$, Leonardo Disperati ${ }^{1}$, José Luís Zêzere ${ }^{2}$, Raquel De Melo ${ }^{2}$, and Sérgio Oliveira ${ }^{2}$ \\ ${ }^{1}$ Department of Physical, Environmental and Earth Science, University of Siena, Siena, Italy (enrico.daddario@unisi.it) \\ ${ }^{2}$ Centre for Geographical Studies, Institute of Geography and Spatial Planning, Universidade de Lisboa, Lisbon, Portugal
}

Shallow landslide susceptibility modelling at regional scale may be performed using both a physically based and statistical approach. For the same area, these two approaches can have inconsistent results, mainly because the two methods are conceptually different. Physically based models are based on the infinite slope model and consists on the computation cell by cell of a safety factor comparing between driving and resisting forces. The assumption that landslides occur in slopes that are characterized by predisposing factors similar to those in which landslides have occurred in the past, is the concept behind the statistical models. The aim of this work is to compare the two approach and investigate the differences between the two models. The study area is located in northern Tuscany, central Italy, in which an extensive field survey highlighted that about $60 \%$ of landslides involve bedrock. For this reason, we developed a physically based susceptibility analysis taking into account both the surficial layer (slope deposit, SD) and the underlying layer (BR), characterized by weathered and fractured bedrock. This model is compared to the statistically based one, which take into account topographic and geologic predisposing factor as well as bedrock geo-mechanical properties, such Geological Strength Index (GSI), Schmidt hammer rebound values (Rv) and Joint density (Jv). The accuracy of the models is evaluated using a multi-temporal landslide inventory, in which involving bedrock landslides are distinct from slope deposits landslides. Within this general framework results are discussed regarding the model's predictive capacity and spatial agreement. 